\title{
Improving Polymer Based Photovoltaic Devices by Reducing the Voltage Loss at the Donor-Acceptor Interface
}

Date J. D. Moet ${ }^{1}$, Lenneke H. Slooff ${ }^{1}$, Jan M. Kroon ${ }^{1,2}$, Svetlana S. Chevtchenko ${ }^{2,3}$, Joachim Loos $^{2,3}$, Marc M. Koetse ${ }^{2,4}$, Jorgen Sweelssen ${ }^{2,5}$, and Sjoerd C. Veenstra ${ }^{1,2}$

${ }^{1}$ Solar Energy, ECN, P.O. Box 1, Petten, NL-1755ZG, Netherlands

${ }^{2}$ Dutch Polymer Institute, Eindhoven, NL-5600 AX, Netherlands

${ }^{3}$ Laboratory of Polymer Technology, Eindhoven University of Technology, P.O. Box 513, Eindhoven, $5600 \mathrm{MB}$, Netherlands

${ }^{4}$ Holst Centre / TNO, Hightech Campus 48, Eindhoven, 5656 AE, Netherlands

${ }^{5}$ Science and Industry, TNO, P.O. Box 6235, Eindhoven, 6500 HE, Netherlands

\section{ABSTRACT}

This paper discusses the characterization and optimization of organic solar cells based on a bulk heterojunction consisting of an alternating copolymer, containing a fluorene and a benzathiadiazole unit with two neighboring thiophene rings, and a fullerene derivative (PCBM). The resulting power conversion efficiency amounts $3.9 \pm 0.2 \%\left(\mathrm{AM} 1.5,100 \mathrm{~mW} / \mathrm{cm}^{2}\right)$ and these polymer solar cells are therefore considered auspicious for further research.

\section{INTRODUCTION}

Important progress has been made in the field of solar energy since the first crystalline silicon solar cell based on a p-n junction was presented in 1954. Extensive research on various inorganic semiconductors has revealed that crystalline silicon is by far the most applicable. With power conversion efficiencies exceeding $15 \%$, present-day crystalline silicon solar cells appear to be suitable replacements for conventional sources of electricity. However, the high production costs of crystalline silicon currently still narrow its potential.

Since the discovery of electrical conductivity in doped polyacetylene in 1977 [1], much attention has been drawn to conjugated polymers. It was realized that this class of organic materials offers advantageous properties as compared to inorganic semiconductors. Advantages include the mechanical flexibility of organic materials, the tunability of their opto-electronic properties, easy incorporation in various kinds of devices and, above all, low-cost fabrication of these devices [2]. The high potential of conjugated polymers in solar cell applications has already become visible in polymer:fullerene bulk heterojunction solar cells with power conversion efficiencies approaching $5 \%$. There remains room for improvement, as device model calculations predict ultimate efficiencies exceeding $10 \%[3,4]$.

In recent years, polyfluorenes have gathered much attention in organic light emitting diode (OLED) research, because of their specifically good transport properties, stability (both thermal and water-/air-stability) and tunability. Polyfluorene-based polymers with lower band gap energies have been synthesized in attempts to harvest more light at higher wavelengths, i.e., beyond the visible part of the sun's spectrum. 
Promising results have been reported for solar cells based on various kinds of polyfluorene derivatives, in particular, the work in the groups of Andersson and Inganäs should be mentioned here [5-12].

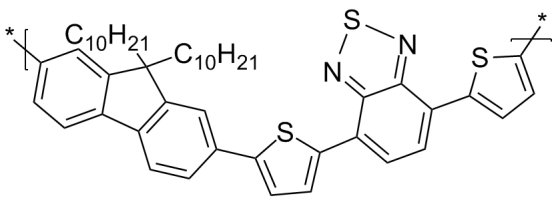

PF10TBT

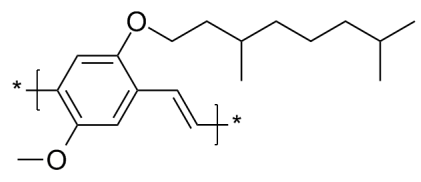

MDMO-PPV

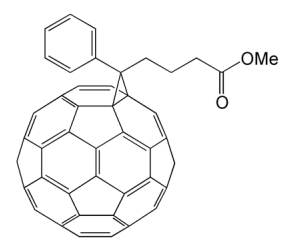

[C60]PCBM

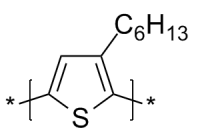

P3HT

Figure 1. Chemical structures and commonly used abbreviations of typical materials used in polymer solar cells.

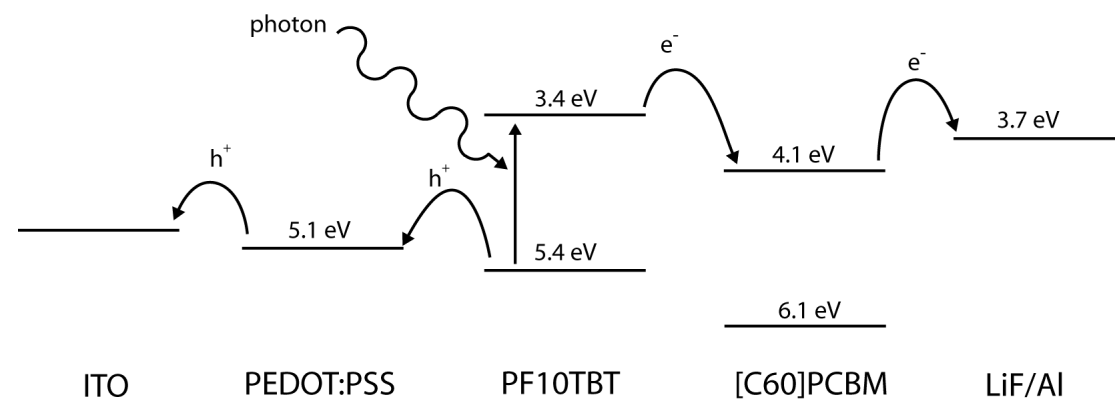

Figure 2. Energy band diagram of a solar cell with an active layer composed of PF10TBT and [C60]PCBM. The indicated energies are the work functions of the electrodes and the $\mathrm{HOMO} / \mathrm{LUMO}$ levels of the donor and acceptor.

The polymer investigated in this study is PF10TBT (figure 1). A particularly interesting property of this material arises from its lower-lying energy levels, which increase the $\mathrm{HOMO}_{\text {donor }}$ - $\mathrm{LUMO}_{\text {acceptor }}$ difference when compared to P3HT. This is illustrated in figure 2. Thus, a higher open-circuit voltage is expected. Upon optimization, it might be possible to increase the extracted short-circuit current in order to obtain an overall increase in the power conversion efficiency. The driving force for charge separation is reduced to about $0.4 \mathrm{eV}$ for the PF10TBT:[C60]PCBM combination, which is expected to be just enough. [13-15] 


\section{EXPERIMENT}

Synthesis of poly(9,9-didecanefluorene-alt-(bis-thienylene)benzotiadiazole) (PF10TBT)

General techniques: solvents from Biosolve, Sigma Aldrich and reagents were used as received. The compounds were characterized by ${ }^{1} \mathrm{H}-\mathrm{NMR}$ on a Varian Mercury $200 \mathrm{MHz}$ apparatus, in deuterated chloroform solutions at 298K. TMS was used as internal standard. The numberaverage molecular weight $\left(\mathrm{M}_{\mathrm{n}}\right)$ and weight average molecular weight $\left(\mathrm{M}_{\mathrm{w}}\right)$ were determined by size exclusion chromatography (SEC), using a series of monodispersed polystyrene standards using 1,3,5-trichlorobenzene as eluent.

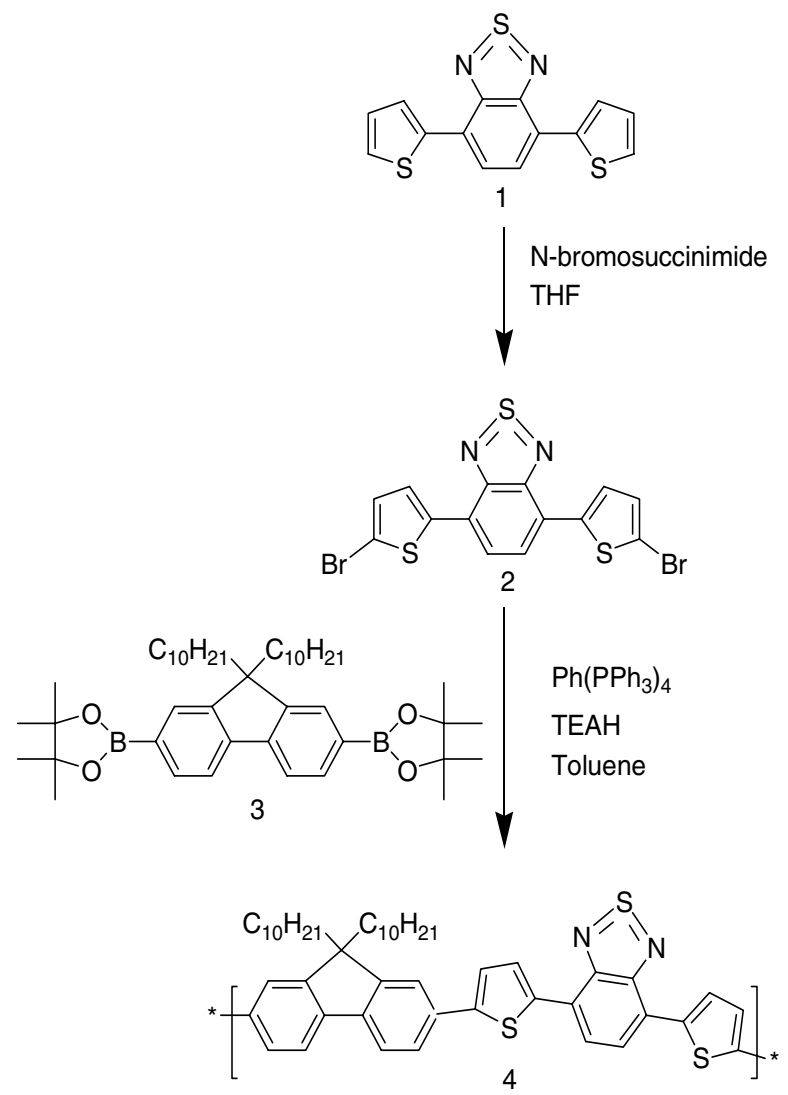

Scheme 1. Synthesis of monomer and polymer

The synthesis of bis-4,7-(thien-2-yl)-2,1,3-benzothiadiazole (1)was performed according to reference [16]. This material was brominated with N-bromosuccinimide to form 4,7-Bis(5bromo-2-thienyl)-2,1,3-benzothiadiazole () . The synthesis of 2,7-bis(4',4',5',5'-tetramethyl1',3',2'-dioxaborolan-2'-yl)-9,9-didecylfluorene (3) was performed according to reference [5]. The polymerization is performed by a Suzuki cross-coupling reaction between compound $\underline{\mathbf{2}}$ and the borolane compound $\underline{\mathbf{3}}$. To a mixture of carefully purified $\underline{\mathbf{2}}(0.25 \mathrm{~g}, 0.55 \mathrm{mmol})$ and $\underline{\mathbf{3}}(0.38 \mathrm{~g}$; $0.55 \mathrm{mmol})$ in $25 \mathrm{ml}$ toluene, a catalytic amount of freshly prepared $\mathrm{Pd}(0)\left(\mathrm{PPh}_{3}\right)_{4}$ was added. The mixture was extensively degassed and left stirring for 10 minutes, $1.8 \mathrm{ml}$ of a tetraethylammoniumhydroxide (TEAH) solution in water $(20 \mathrm{wt} \%)$ was added. The mixture was 
vigorously stirred at $110^{\circ} \mathrm{C}$ for $4.5 \mathrm{~h}$ under a nitrogen atmosphere. A catalytic amount of $\mathrm{Pd}(0)\left(\mathrm{PPh}_{3}\right)_{4}$, $1 \mathrm{ml}$ TEAH solution, $0.6 \mathrm{~g}$ (2.9 mmol) (4,4,5,5-tetramethyl-1,3,2-dioxaborolan-2yl)-benzene (capping agent) were added and the reaction mixture was refluxed for another 24 hours. After cooling down to room temperature, chloroform and water were added. The organic layer was separated and stirred twice with a $2 \%$ sodium cyanide solution, washed three times with water, dried over $\mathrm{MgSO}_{4}$ and evaporated. The solid residue was dissolved in as little chloroform as possible and precipitated in methanol. This process was repeated 3 times. Finally, the product was dried in vacuum, yielding $0.31 \mathrm{~g}$ (approx. $77 \%$ ) of a dark red polymer. The PF10TBT polymer () had a $\mathrm{M}_{\mathrm{w}}$ of $58.4 \mathrm{~kg} / \mathrm{mol}$ with a polydispersity index (PDI) of 3.3 (measured at $80^{\circ} \mathrm{C}$ ).

${ }^{1} \mathrm{H}-\mathrm{NMR}\left(200 \mathrm{MHz}, \mathrm{CDCl}_{3}, \mathrm{ppm}\right) \delta[\mathrm{ppm}], 0.6-1.5$ (m, 38H), $2.10(\mathrm{~b}, 4 \mathrm{H}), 7.52(2 \mathrm{H})$, 7.6-7.8 (b, 6H), 7.96 (b, 2H), 8.16 (b, 2H).

\section{Device preparation}

Glass substrates with a patterned indium tin oxide layer, provided by Philips, were thoroughly cleaned in a laminar flow box to minimize the possibility of electrical shorts due to impurities. First, the substrates were scrubbed with a water/extran mixture. Then, after rinsing with demiwater, the samples were placed in an ultrasonic bath for 10 minutes in ultra-pure demiwater. Finally, the substrates were rinsed with isopropyl alcohol (IPA) and placed in an ultrasonic bath with the same solvent for 10 minutes. Drying was done in an oven at $120^{\circ} \mathrm{C}$ for 10 minutes. Subsequently the substrates were placed in a UV-ozone photoreactor (UVP PR-100) for at least 20 minutes.

As a buffer layer, $250 \mu \mathrm{L}$ of an aqueous PEDOT:PSS (HC Starck) solution, filtered with a $0.45 \mu \mathrm{m}$ PVDF filter, was spin coated on top of the UV-ozone cleaned substrates with a Laurell WS-400A-6NPP/LITE spin coater. A spreading step of 5 seconds at $500 \mathrm{rpm}$ was followed by a drying step of 100 seconds at $1500 \mathrm{rpm}$.

Spin coat solutions were prepared by dissolving $2.5 \mathrm{wt} . \%$ [C60]PCBM (acquired from Solenne BV) in chlorobenzene and stirring at $70^{\circ} \mathrm{C}$ for at least 2 hours. After dissolving the acceptor material, the appropriate amount of PF10TBT (provided by TNO, JS517) was added to the [C60]PCBM solution in order to give a polymer concentration of $0.6 \mathrm{wt} \%$ after addition of chlorobenzene to get the desired [C60]PCBM concentration of $2.4 \mathrm{wt} \%$, yielding a polymer:fullerene ratio of 1:4 by weight. The solution was left stirring overnight at $70^{\circ} \mathrm{C}$. The PF10TBT:[C60]PCBM solution in chlorobenzene was filtered with a $5 \mu \mathrm{m}$ PFTE filter prior to spin coating.

A typical spin coating procedure consisted of a spreading step of 5 seconds at $500 \mathrm{rpm}$, followed by a drying step (100 seconds) at 750 up to $3500 \mathrm{rpm}$, depending on the desired thickness and applied solvent. After transferring the samples to a glove box, the samples were placed in a high vacuum $\left(\sim 10^{-6}\right.$ mbar $)$ bell jar for electrode evaporation. An interfacial layer consisting of $1 \mathrm{~nm}$ of $\mathrm{LiF}$ was applied before the application of a $80 \mathrm{~nm}$ Al layer. Hole-only devices were constructed by evaporating $15 \mathrm{~nm}$ of Pd, followed by $80 \mathrm{~nm}$ of $\mathrm{Au}$. This ensures efficient electron blocking because of a high electron injection barrier. Evaporation was initially performed with a low rate $(0.1 \mathrm{~nm} / \mathrm{s})$. Beyond layer thicknesses of about $4 \mathrm{~nm}$, the evaporation rate was increased to 0.5 to $1.5 \mathrm{~nm} / \mathrm{s}$. 


\section{$\underline{\text { Device characterization }}$}

The current densities in the dark and under illumination were recorded by a measurement setup containing a Keithley 2400 SourceMeter wired to a sample holder in the nitrogen-filled glove box. The sample was illuminated by a halogen lamp. An automated rotating filter wheel was used to record the current densities at various wavelengths for external quantum efficiency (EQE) measurement. A silicon reference cell with known spectral response was used for calibration purposes. This enabled the measurement program on the computer to calculate an estimation of the short-circuit current of the organic solar cell under $1000 \mathrm{~W} / \mathrm{m}^{2}$, AM1.5 illumination.

The currents measured by the Keithley (for the voltage ranging from $-2 \mathrm{~V}$ to $+2.5 \mathrm{~V}$ ) were divided by the area of the overlapping ITO and $\mathrm{LiF} / \mathrm{Al}$ or $\mathrm{Pd} / \mathrm{Au}$ electrodes. The active areas of each of the four cells on substrate are: $0.093,0.164,0.364$ and $1.01 \mathrm{~cm}^{2}$. Whenever a solar cell performed exceptionally well, the overlap was again determined using an optical microscope.

The resulting measured area value was used to calculate the current density from the current-voltage characteristics of the organic solar cell under simulated AM1.5 illumination from a Spectrolab XT-10 solar simulator. The mismatch factor was calculated using a recent spectrum of the simulator lamp, the spectral response of the used reference cell and the spectral response of the polymer:fullerene cell.

Temperature-dependent dark current measurements on hole-only devices were performed at the University of Groningen, in a nitrogen-filled glove box equipped with a sample holder through which a cold nitrogen flow could be regulated. Temperatures down to $215 \mathrm{~K}$ could be achieved. The activation energy $\Delta$ of the fitted zero-field hole mobility $\mu_{p}(0)$ could then be calculated from plots of $\mu_{p}(0)$ versus $1 / \mathrm{T}$, according to the Arrhenius-type relation $\mu_{p}(0)=\mu_{0} \exp (-$ $\Delta / \mathrm{kT})$.

Optical characterization of the polymer films was carried out with a HP 8453 UV-Vis spectrophotometer. TEM measurements were conducted on a Jeol JEM-2000FX transmission electron microscope operated at $80 \mathrm{kV}$.

\section{RESULTS and DISCUSSION}

Efficient, reproducible bulk heterojunction solar cells have been made with PF10TBT as electron donor and [C60]PCBM as electron acceptor with power conversion efficiencies up to $3.9 \pm 0.2 \%$ under $1000 \mathrm{~W} / \mathrm{m}^{2}$, simulated AM1.5 illumination. The best performing devices were spun cast from a chlorobenzene solution and had layer thicknesses in the range from 150 to 250 $\mathrm{nm}$ (see also the following sections). The open-circuit voltage amounted to $995 \mathrm{mV}, J_{\mathrm{sc}}$ to 6.8 $\mathrm{mA} / \mathrm{cm}^{2}$ and the fill factor to $59 \%$ (see figure 3(a)). 


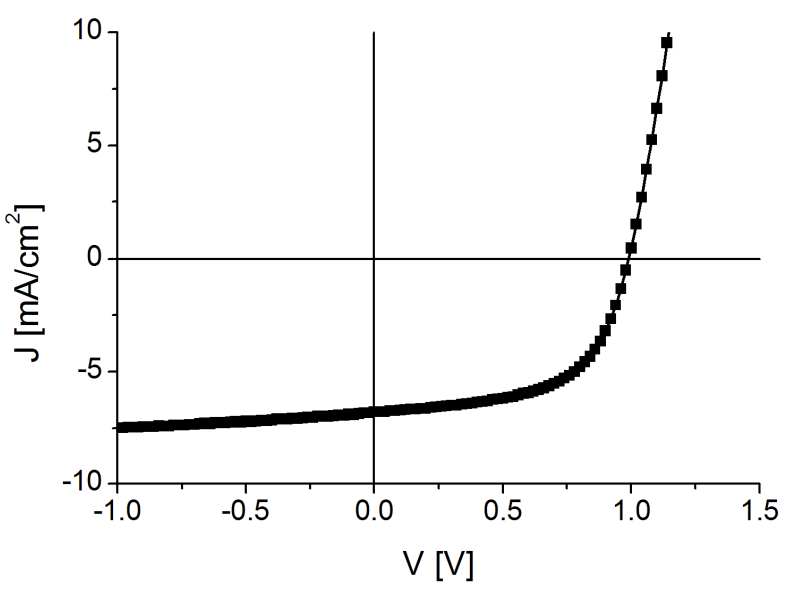

a)

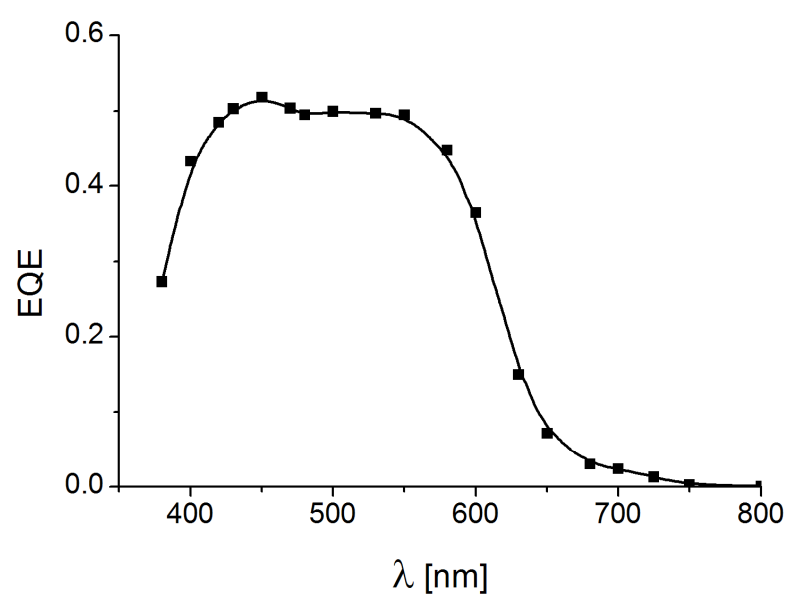

b)

Figure $3 \mathrm{~J}$ - $V$-characteristics under illumination of a PF10TBT:[C60]PCBM solar cell with $\eta=3.9 \%$. The lines are drawn as a guide to the eye: (a) current density under AM1.5, $1 \mathrm{~kW} / \mathrm{m}^{2}$ illumination; (b) external quantum efficiency.

As can be seen in figure 3(b), the cells show spectral response in the range from 400 to $750 \mathrm{~nm}$ with local maxima at approximately 450 and $530 \mathrm{~nm}$. From the EQE data, an AM1.5 short-circuit current $J_{\mathrm{sc}}$ of $6.8 \mathrm{~mA} / \mathrm{cm}^{2}$ was calculated, which is in excellent agreement with the measured value of $6.8 \mathrm{~mA} / \mathrm{cm}^{2}$. About $50 \%$ of the incoming photons with $450 \mathrm{~nm}<\lambda<550 \mathrm{~nm}$ contribute to the current in the external circuit.

The maximum EQE and short-circuit current density are considerably smaller than those of optimized P3HT-based devices (typically $10-11 \mathrm{~mA} / \mathrm{cm}^{2}$ ), although the band gaps are similar. This might at least partially arise from the lowered LUMO-LUMO offset between donor and acceptor and, thus, a lower driving force for charge separation. If this is the case, an electron accepting material with a higher electron affinity could make a difference and might improve the $\mathrm{EQE}$ and $J_{\mathrm{sc}}$ even further.

Ultimately, the fill factor $(F F \sim 60 \%)$ is somewhat lower than in P3HT:PCBM solar cells giving $\sim 67 \%$ for comparable cell geometries. Some improvement may still be possible. Its dependence on factors such as layer thickness and light intensity might yield more understanding on the influence of recombination and space-charge on device performance.

In P3HT:PCBM devices, $V_{\mathrm{oc}}$ is about $0.6 \mathrm{~V}$ and $\mathrm{HOMO}_{\text {donor }}-\mathrm{LUMO}_{\text {acceptor }}$ approximately $0.9 \mathrm{eV}$. Thus, a voltage loss of $0.3 \mathrm{~V}$ is found in such devices, which is commonly attributed to contact losses.[4] Here, we find the same: $\mathrm{HOMO}_{\text {donor }}-\mathrm{LUMO}_{\text {acceptor }}$ is $1.3 \mathrm{eV}$ and $V_{\text {oc }}$ amounts to $1.0 \mathrm{~V}$, thus, again we find a loss of $0.3 \mathrm{~V}$. A similar voltage loss is found in MDMO-PPV:PCBM devices. This is an important point, the loss of $0.3 \mathrm{~V}$ is a constant in these devices and independent of the energy difference between $\mathrm{HOMO}_{\text {donor }}-\mathrm{LUMO}_{\text {acceptor}}$. Optical and cyclic voltammetry measurements reveal a similar band gap for P3HT and PF10TBT of 1.9 $\mathrm{eV}$. So, with respect to the energy levels of P3HT, the HOMO and LUMO levels of PF10TBT shift downward by $0.4 \mathrm{eV}$. In the photovoltaic device, the difference between the $\mathrm{HOMO}_{\text {donor }}$ and $\mathrm{LUMO}_{\text {acceptor }}$ levels is thus increased by $0.4 \mathrm{eV}$, which leads directly to an increase of the $V_{\mathrm{oc}}$ with $0.4 \mathrm{~V}$ to $1.0 \mathrm{~V}$. 
The overall effect of a higher $V_{\text {oc }}$ and a lower $J_{\text {sc }}$ and $F F$ on the magnitude of $\eta$ turns out to be negligible: the promising power conversion efficiency is comparable to those found for P3HT-based cells.

\section{Influence of solvents}

Four common organic solvents were used to process the polymer solar cells. The solutions were spin coated in air. The polymer/fullerene combination dissolved best in chlorobenzene (CB) and 1,2-dichlorobenzene (ODCB). Less reproducible results were obtained with chloroform (CF) and toluene (TO). The TO samples showed poor performance in terms of $J$ - $V$-parameters (see figure 4). As indicated before, the best results were obtained with $\mathrm{CB}$ or $\mathrm{CF}$ as solvent. This observation is supported with TEM images; figures 5(a) and 5(b) show a clear phase separation in active layers spin coated from CB and CF solutions, respectively. In the case of $\mathrm{CF}$, white some spherical features with diameters of $\sim 100 \mathrm{~nm}$ are found. The origin of these features is not yet clear. The electronic properties of $\mathrm{CB}$ and $\mathrm{CF}$ films are similar, which indicates that the white spots are of no influence in this respect.
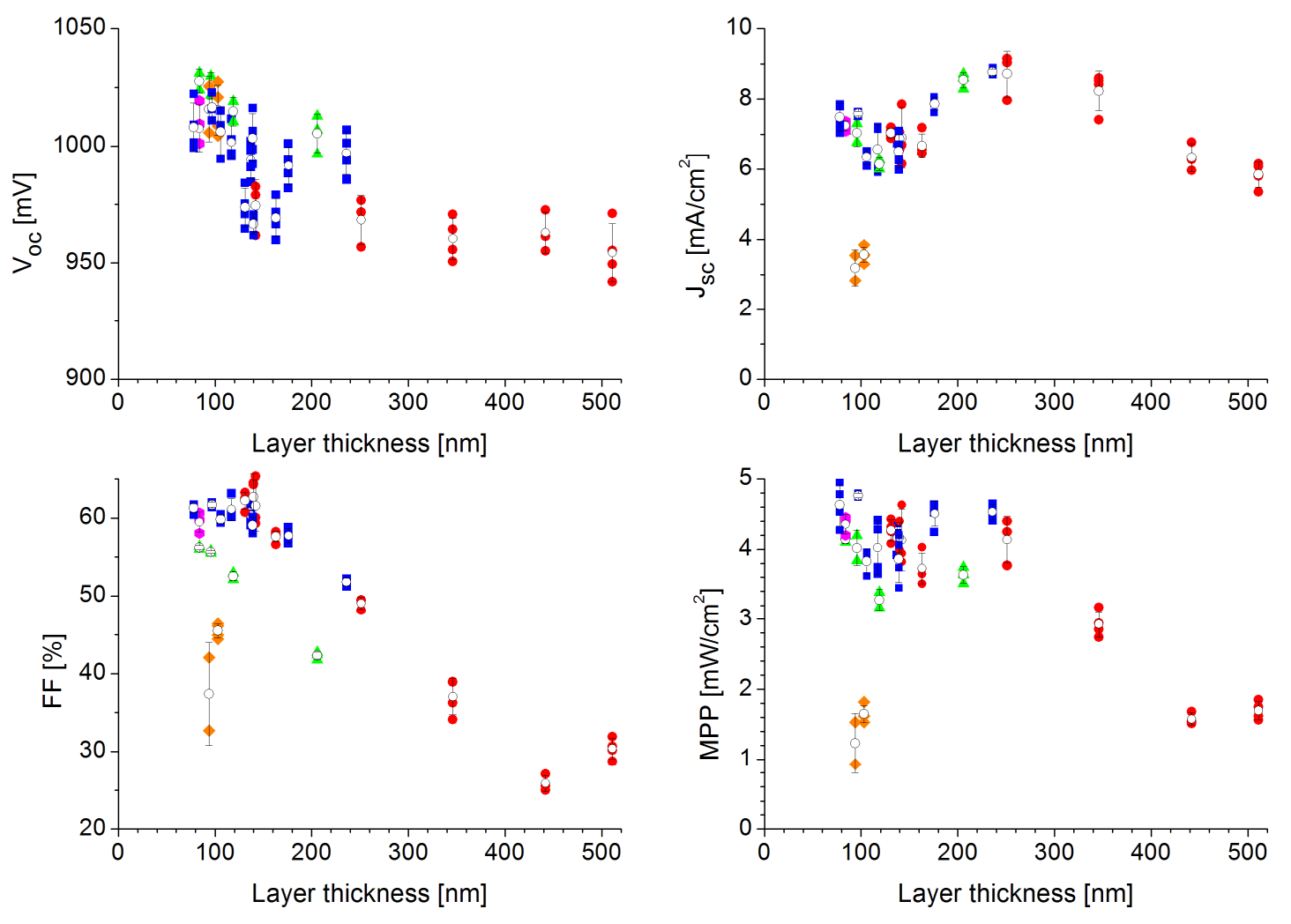

Figure $4 \mathrm{~J}$ - $V$-parameters as a function of layer thickness for four different solvents, viz. chlorobenzene (blue squares), chloroform (red circles), 1,2-dichlorobenzene (green triangles) and toluene (orange diamonds). Parameters of devices spin coated from chlorobenzene under a nitrogen atmosphere are indicated in pink hexagons. Averages are indicated with open circles. 
TO samples, see figure 5(d), suffer from the poor solubility of the polymer in this solvent. Obviously the phase separation is on an undesired length scale, which can explain the low $J_{\mathrm{sc}}$ and $F F$ with concurrent preservation of a $V_{\mathrm{oc}} \approx 1.0 \mathrm{~V}$.

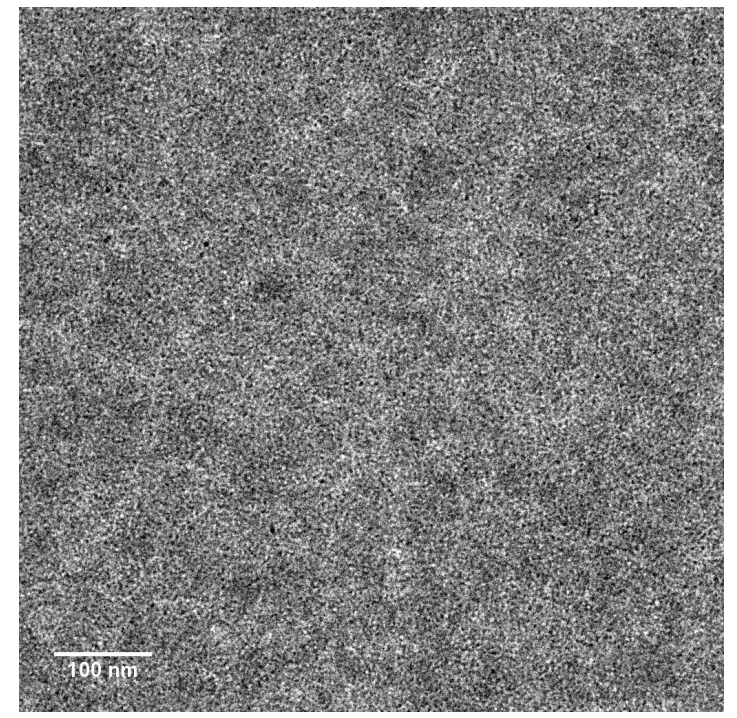

a)

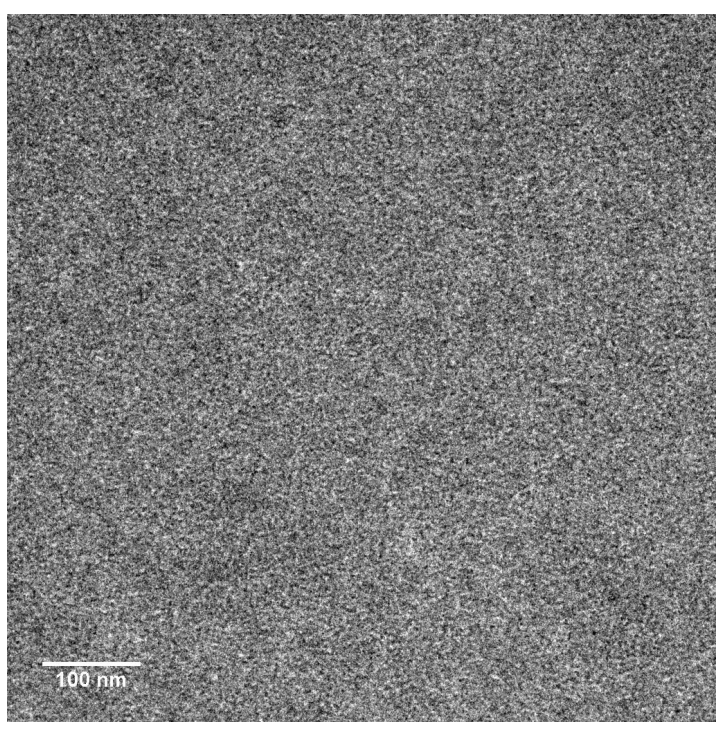

c)

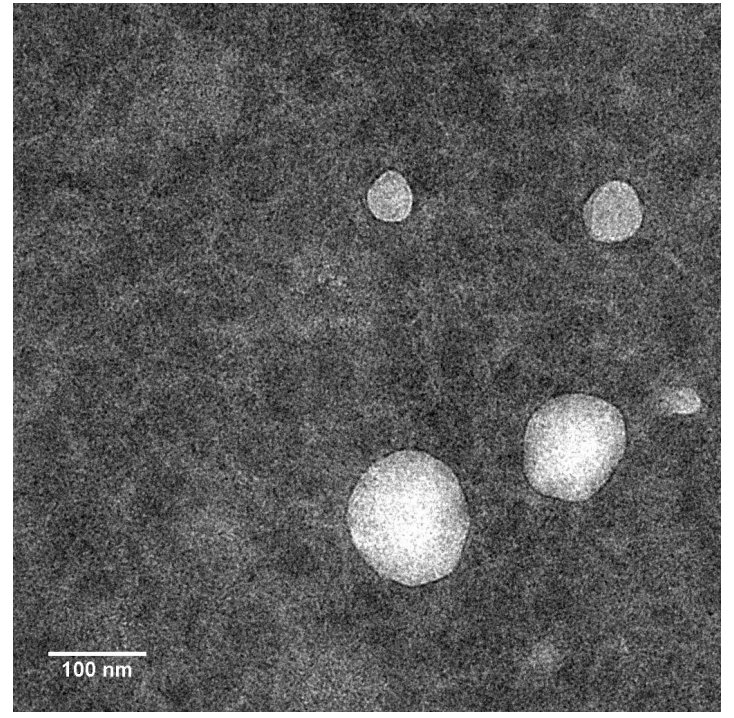

b)

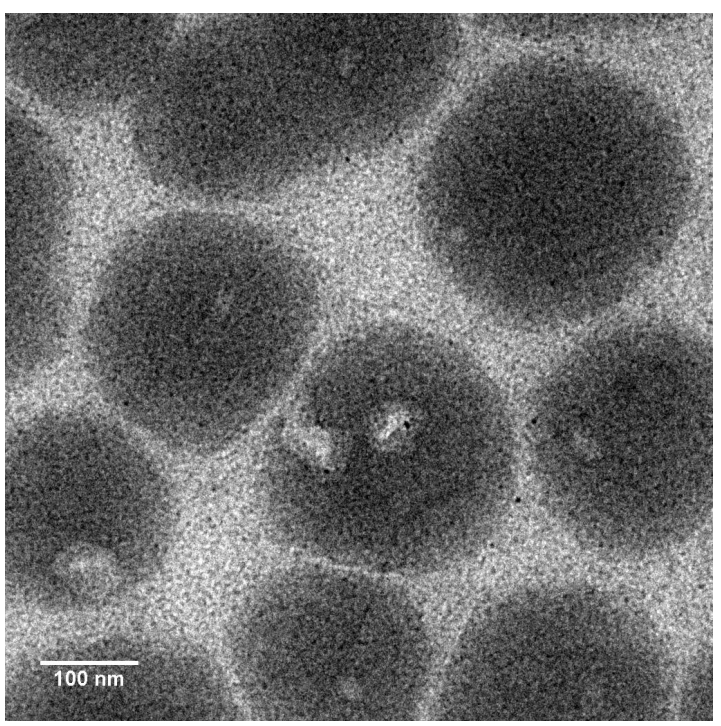

d)

Figure 5. TEM images of solar cells made from different solvents. (a) Chlorobenzene, $L=117$ $\mathrm{nm}$; (b) Chloroform, $L=131 \mathrm{~nm}$; (c) 1,2-dichlorobenzene, $L=119 \mathrm{~nm}$; (d) Toluene, $L=103 \mathrm{~nm}$. The scale bar indicates $100 \mathrm{~nm}$.

An interesting property is revealed for the fill factor of ODCB samples. It is clearly inferior to $F F$ in $C B$ and CF cells for the entire available range of layer thicknesses $(119 \mathrm{~nm}<L<$ $206 \mathrm{~nm}$ ). The TEM image in figure 5(c) shows a very fine phase separation, even better than in 
$\mathrm{CB}$ and $\mathrm{CF}$ films. How this relates to a low FF is not yet clear. Possibly the polymer and/or fullerene-rich regions are too small to have good percolation pathways, however, we have no evidence for this scenario. Another possibility is that the charge carrier mobility of holes in the polymer is reduced by using ODCB, resulting in an earlier onset (in terms of layer thickness) of a space-charge limitation.

The plots of $V_{\text {oc }}$ and $J_{\text {sc }}$ show a clear trend for the three suitable solvents $(\mathrm{CF}, \mathrm{CB}$ and ODCB). $V_{\text {oc }}$ is not very sensitive to solvent variation, as all values are found within $\sim 70 \mathrm{mV}$ variation. Also, there is no significant thickness dependence. In the plot of the short-circuit current, a maximum is found between $200 \mathrm{~nm}<L<250 \mathrm{~nm}$. At layer thicknesses below $100 \mathrm{~nm}$, $J_{\text {sc }}$ seems to increase again. This is attributed to optical interference effects. Together with a higher $F F$ for thinner films, this gives a power conversion efficiency that is comparable to the ones for films with $L>150 \mathrm{~nm}$ (see the $M P P$ plot in figure 4).

The opposite trends of $J_{\mathrm{sc}}$ and $F F$ versus layer thickness result in a rather wide plateau of maximum power points ( $M P P$ 's) higher than $4 \mathrm{~mW} / \mathrm{cm}^{2}$ up to $L \approx 240 \mathrm{~nm}$. In thicker layers, a loss mechanism limits the performance, possibly bimolecular recombination or space-charge. The fill factor $(F F)$ decreases dramatically with increasing layer thickness and dominates $M P P$ for $L>240 \mathrm{~nm}$.

\section{Influence of composition}

The $J$ - $V$-parameters for solar cells with different PF10TBT:[C60]PCBM weight ratios as a function of layer thickness are shown in figure 6. Polymer:fullerene weight ratios of 1:1 (50 wt.\% PCBM), 1:2 (67 wt.\% PCBM) and 1:4 (80 wt.\% PCBM) have been used.

A clear dependence of $V_{\text {oc }}, F F$ and MPP on PCBM content can be found in these plots. The open-circuit voltage is highest for the lowest PCBM concentrations, although the variation is again only $\sim 70 \mathrm{mV}$. A similar observation was made by others and attributed to a change in material composition close to the electrodes.[17-18] Whereas the short-circuit current density for 67 and $80 \mathrm{wt} . \%$ PCBM is comparable, its value at $50 \mathrm{wt} . \%$ is significantly lower. For the latter, light absorption does not seem to be a limiting factor of $J_{\text {sc }}$; a 1:1 film absorbs best, because of its relatively high polymer content. However, the negative slope of $J_{\text {sc }}$ versus layer thickness for 1:1 devices might indicate a limitation due to less convenient transport properties in this film.

$F F$ is strongly ratio-dependent. This is illustrated for samples with comparable layer thickness in figure 7. Although $V_{\mathrm{oc}}$ and $J_{\mathrm{sc}}$ at $80 \mathrm{wt} . \%$ PCBM are lower than at $67 \mathrm{wt} . \%$ PCBM, the higher $F F$ of the former compensates for this deficiency to give a higher MPP.

To disentangle the consequences that ratio variation has for light absorption from the discussion on its influence on device performance, we compared the external quantum efficiency of two cells (50 and 67 wt.\% PCBM) at the wavelength where the absorbance in the active wavelength range of the polymer was equal.[9] This is done in figure 7. Unfortunately, no 80 wt.\% PCBM solar cell was available for this experiment. Thus, at equal absorption, the EQE of 50 wt.\% PCBM films is considerably ( 14\% relative) lower than that of its 67 wt.\% PCBM counterpart. This illustrates that in active layers with such a low amount of PCBM, charge carrier separation and/or transport is probably inadequate, resulting in a low $J_{\mathrm{sc}}$. 

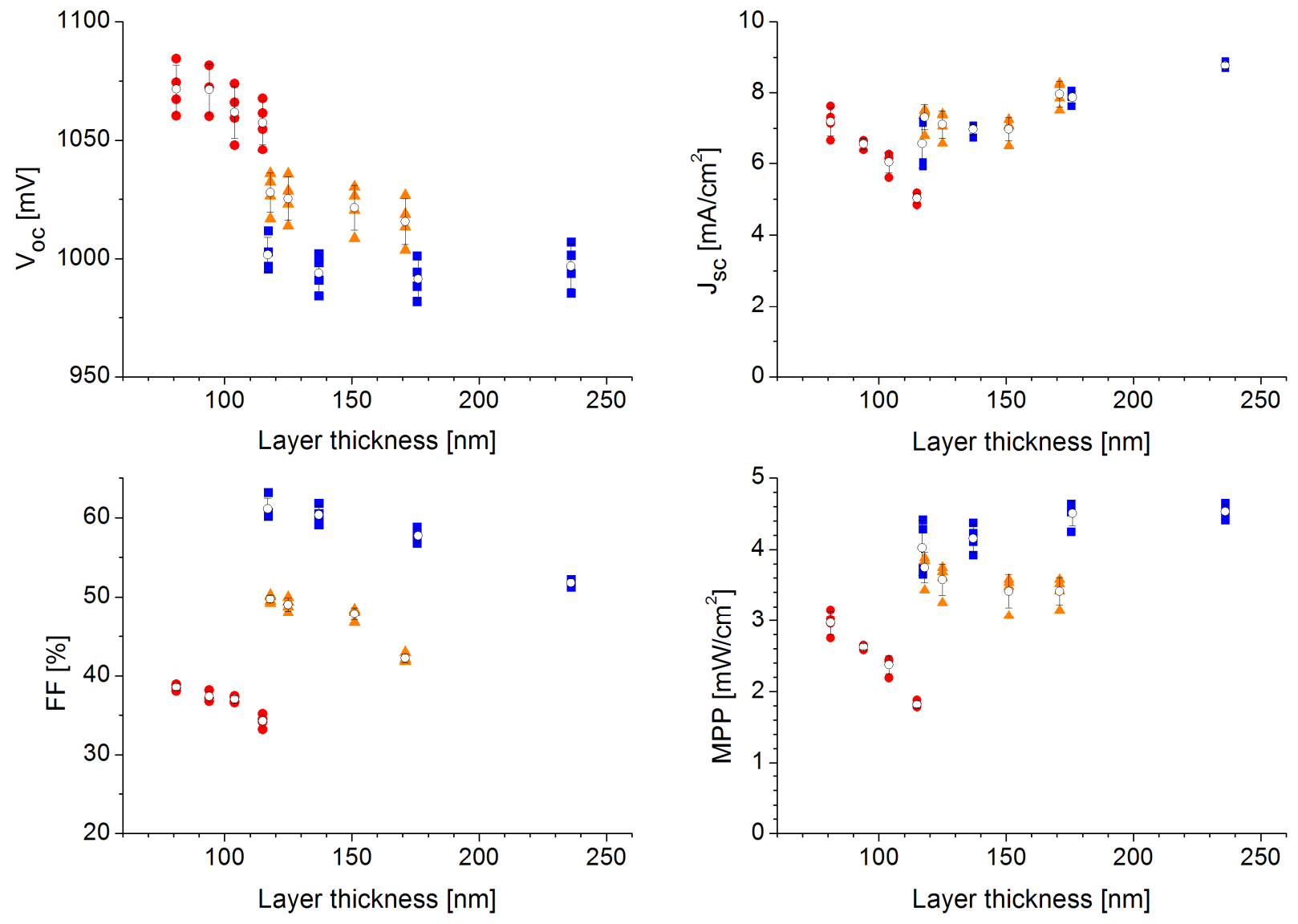

Figure 6. $J$ - $V$-parameters of solar cells with different PF10TBT:[C60]PCBM weight ratios. The data are shown for $80 \mathrm{wt}$ \% PCBM (blue squares), $67 \mathrm{wt} \%$ PCBM (orange triangles) and 50 wt.\% PCBM (red circles).
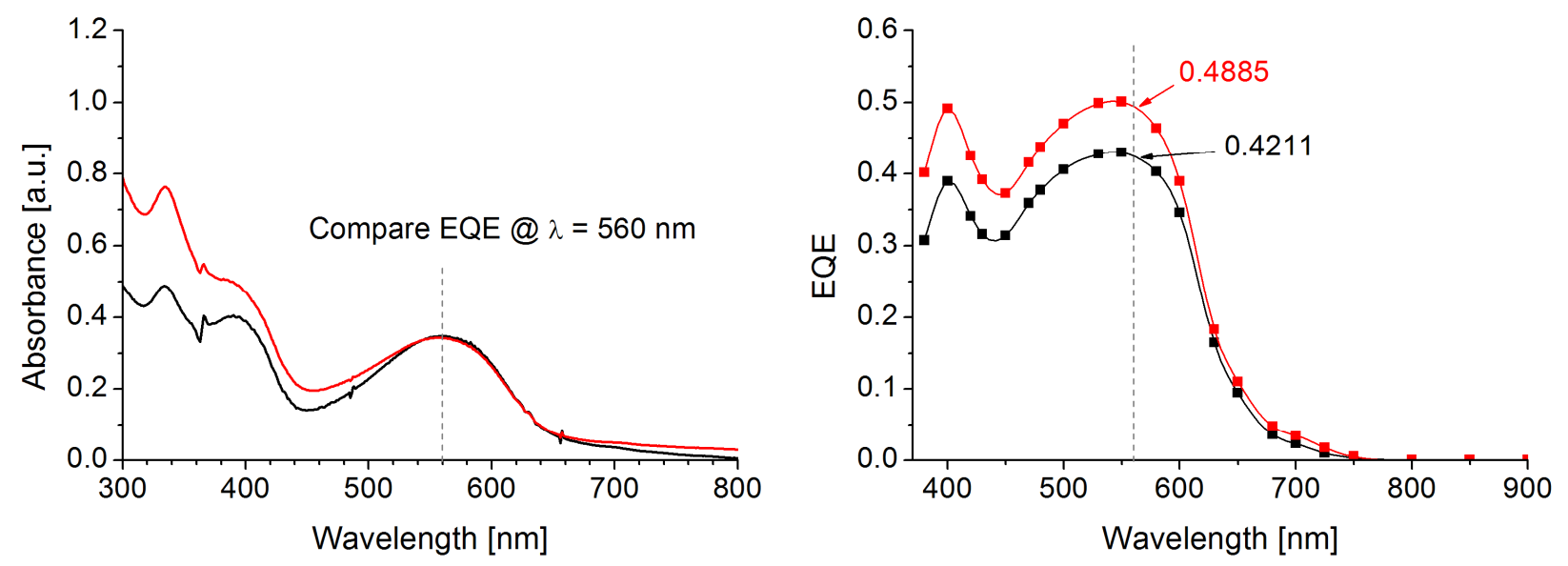

Figure 7. EQEs of a 50 (black) and 67 (red) wt.\% PCBM solar cell, compared at the wavelength where their absorbance is equal. The lines in the figure to the right are drawn to guide your eye. 


\section{Hole transport}

In general, two limitations on charge transport can be distinguished: injection-limited conduction and space-charge-limited conduction (SCLC). In the first case, a Schottky region close to the contact is less conductive than the rest of the sample, therefore limiting the total possible current. The second regime, SCLC, results from a space-charge region near the injecting electrode, which causes a redistribution of the electric field intensity that controls the charge transport properties in the bulk of the device.

Blom et al. demonstrated in 1996 that the hole transport in PPV is space-charge-limited and not injection-limited [19]. This observation, with the assumption that there are no traps present in the forbidden band gap that limit the charge transport, makes the interpretation of current-voltage data somewhat easier. Characteristic for the trap-free SCLC regime is the square dependence on voltage $V$ and inverse cubic dependence on layer thickness $L$ of the current density $J$, given by the Mott-Gurney law [20]

$$
J=9 / 8 \varepsilon_{0} \varepsilon_{r} \mu_{p} V^{2} / L^{3},
$$

in which $\varepsilon_{0}$ is the permittivity of vacuum, $\varepsilon_{r}$ is the dielectric constant of the material and $\mu_{p}$ is the hole mobility.

Deviations from this law at higher fields have been attributed to a field-dependent mobility [21]. A field dependence with a stretched exponential form relates the hole mobility to a zero-field mobility $\mu_{p}(0)$, a field activation parameter $\gamma$ and the electric field according to [19,22]

$$
\mu_{p}=\mu_{p}(0) \exp (\gamma /(E))
$$

It is stressed that this Poole-Frenkel-like half-power field dependence of the mobility does not arise from charged traps, but results from the intrinsic charge transport properties in disordered semiconductors [23,24]. Murgatroyd showed that the incorporation of such a mobility in the expression for $J$ can be approximated by [25]

$$
J \approx 9 / 8 \varepsilon_{0} \varepsilon_{r} \mu_{p}(0) V^{2} / L^{3} \exp (0.891 \gamma(V / L)) .
$$

In this equation, the voltage $V$ must be the potential difference over the active layer, which is smaller than the applied voltage due to a voltage drop over the hole-injecting contact $\left(V_{\mathrm{Rs}}\right)$. Furthermore, the relation obviously only holds in the SCLC regime, which occurs above a so-called built-in voltage $V_{\mathrm{bi}}$ that arises from the work function difference of the contacts. For a correct determination of the transport parameters $\mu_{p}(0)$ and $\gamma$, we must therefore plot the current density $J$ versus $V-V_{\mathrm{bi}}-V_{\mathrm{Rs}}$.

Several groups have reported on an enhanced hole mobility in polymer:fullerene blends with respect to the pristine material. A dramatic effect is found in MDMO-PPV:PCBM films [26], in which the hole mobility of MDMO-PPV increases several orders of magnitude upon addition of 80 wt.\% PCBM, whereas the effect in specific polyfluorene:fullerene composite layers is less pronounced, yet still present $[5,9]$.

It is noted that the discussion on the fundamental mechanism of charge transport in disordered organic semiconductors still continues. Some researchers prefer to interpretate the $J$ $V$-characteristics in terms of (slightly modified) Poole-Frenkel (PF) currents instead of SCL 
currents [27-29]. In this PF-like mechanism, electrostatic Coulomb interactions between the charge carriers in the bulk of the organic material are considered to qualitatively account for the observed field and temperature dependence of $J$. The interpretation of charge transport adopted in this study, however, is based on field-activated space-charge-limited currents.

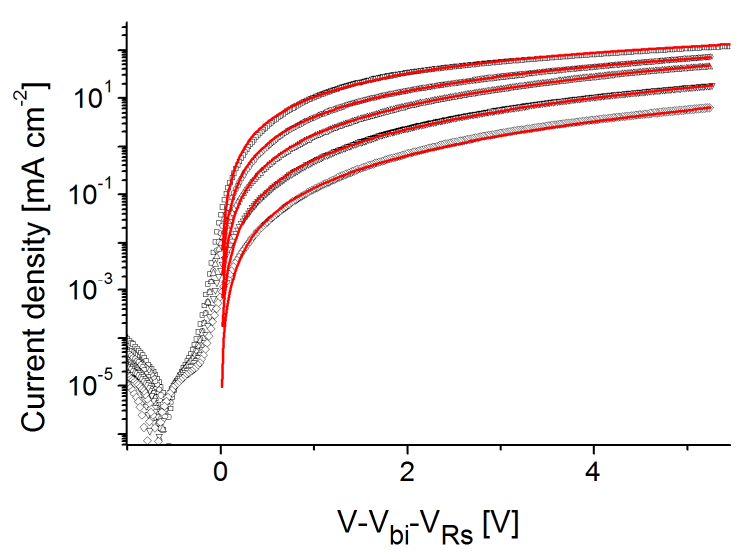

a)

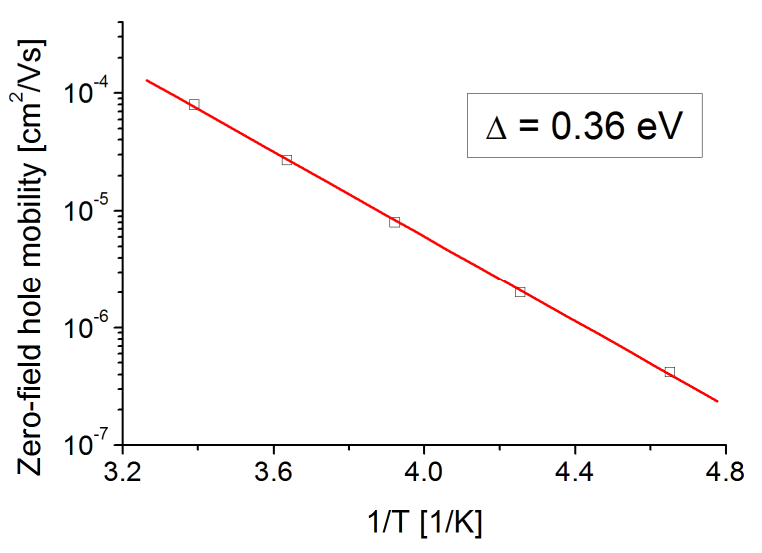

b)

Figure 8. Transport properties in a $239 \mathrm{~nm}$ hole-only device with $80 \mathrm{wt} \%$ PCBM. (a) Dark current density at $295 \mathrm{~K}$ (top curve), $275 \mathrm{~K}, 255 \mathrm{~K}, 235 \mathrm{~K}$ and $215 \mathrm{~K}$ (bottom curve). (b) Fitted temperature-dependent zero-field mobility.

Temperature-dependent $J-V$ measurements on both PF10TBT:PCBM and pristine PF10TBT hole-only devices (ITO/PEDOT/organic layer/Pd/Au) were performed to investigate the influence of PCBM loading on the hole mobility in the polymer. In figure 8(a), the current density in such a device based on a $239 \mathrm{~nm}$ layer of PF10TBT:[C60]PCBM in 1:4 weight ratio is plotted. The fits made with equation 3 show nice agreement with the measurement data. At room temperature, using a spatially averaged dielectric constant of $\varepsilon_{r}=3.5, \mu_{p}(0)$ amounts to $8 \times 10^{-5}$ $\mathrm{cm}^{2} / \mathrm{Vs}$ and $\gamma=-3.6 \times 10^{-5}(\mathrm{~cm} / \mathrm{V})^{0.5}$. The zero-field hole mobility in this system thus has a value somewhat lower than that of MDMO-PPV and P3HT (after thermal annealing) in the presence of 80 wt.\% PCBM $\left(\sim 2 \times 10^{-4} \mathrm{~cm}^{2} / \mathrm{Vs}\right.$ in both cases $)$. A negative value of $\gamma$ is not uncommon [30], as it has also been found in slow-drying P3HT:PCBM cells. The results were closely reproduced with layers of another thickness (see table 1), indicating that we really do measure transport properties.

\begin{tabular}{|l|c|c|c|c|c|c|c|}
\hline Sample & Ratio & Solvent & $L[\mathrm{~nm}]$ & $\mu_{p}(0)\left[\mathrm{cm}^{2} / \mathrm{Vs}\right]$ & $\gamma\left[(\mathrm{cm} / \mathrm{V})^{0.5}\right]$ & $V_{\text {bi }}[\mathrm{V}]$ & $\Delta[\mathrm{eV}]$ \\
\hline \hline $\operatorname{dm} 060614-1$ & $1: 4$ & CB & 239 & $8 \times 10^{-5}$ & $-3.6 \times 10^{-5}$ & 0.6 & 0.36 \\
\hline $\operatorname{dm} 060614-2$ & $1: 4$ & CB & 162 & $7 \times 10^{-5}$ & $-3.8 \times 10^{-5}$ & 0.6 & 0.34 \\
\hline $\operatorname{dm} 060713-2$ & $1: 0$ & CB & 80 & $8 \times 10^{-5}$ & $-3.2 \times 10^{-5}$ & 1.2 & 0.43 \\
\hline $\operatorname{dm} 060614-3$ & $1: 0$ & CF & 101 & $7 \times 10^{-5}$ & $-0.7 \times 10^{-5}$ & 1.7 & 0.37 \\
\hline
\end{tabular}

Table 1: Experimental properties and fit parameters used in the hole transport study. 
The temperature dependence of $\mu_{p}(0)$ reveals an activation energy of $0.36 \mathrm{eV}$. This value can be expected for a mobility of this magnitude and therefore gives an extra confirmation that we measure the right property.

For reference, we made hole-only devices of a single layer of pristine PF10TBT $(\sim 100$ $\mathrm{nm}$ thick). Interestingly, the CF hole-only device showed an activation energy of $\mu_{p}(0)$ close to the value for composite devices (see table 1). All devices show the same mobility, which unambiguously leads to the conclusion that the hole mobility of PF10TBT is not influenced by adding $80 \mathrm{wt} . \%$ [C60]PCBM.

\section{CONCLUSIONS}

We have made highly efficient organic solar cells based on a bulk heterojunction consisting of an alternating copolymer with fluorine and benzathiadiazole (PF10TBT) and the commonly used electron acceptor [C60]PCBM. A power conversion efficiency (AM1.5, 100 $\mathrm{mW} / \mathrm{cm}^{2}$ ) of $3.9 \pm 0.2 \%$ has been achieved, resulting from an open-circuit voltage of $995 \mathrm{mV}$, a short-circuit density of $6.8 \mathrm{~mA} / \mathrm{cm}^{2}$ and a fill factor of $59 \%$.

The selected solvent was chlorobenzene, which yielded devices with similar electronic properties as chloroform, but was much more convenient in processing. The polymer could not be dissolved in toluene and 1,2-dichlorobenzene showed a reduced fill factor compared to chlorobenzene and chloroform, which has not yet been explained. The optimal layer thickness was found between 150 and $250 \mathrm{~nm}$. Also below $100 \mathrm{~nm}$ good cells were constructed, having a relatively high $F F$.

Mixing the polymer with the fullerene in a 1:4 weight ratio (i.e., 80 wt.\% PCBM) gave the best solar cells. Especially the fill factor was found to be strongly dependent on composition. No influence of the PCBM loading on the zero-field hole mobility in the polymer phase $\left(8 \times 10^{-5}\right.$ $\mathrm{cm}^{2} / \mathrm{Vs}$ ) was found.

\section{ACKNOWLEDGMENTS}

The authors would like the thank prof. P. W. M. Blom and his group members for discussions and assistance in measuring the hole mobility of PF10TBT. Drs. D. Veldman is kindly acknowledged for cyclic voltammetry measurements and discussions concerning energy and charge transfer processes. Dr. V. D. Mihailetchi is acknowledged for fruitful discussions especially on charge transport. This work forms part of the research program of the Dutch Polymer Institute (DPI), project \# 524.

\section{REFERENCES}

1. C. K. Chiang, C. R. Fincher Jr., Y. W. Park, A. J. Heeger, H. Shirikawa, E. J. Louis, S. C. Gau, and A. G. MacDiarmid, Phys. Rev. Lett. 39, 1098 (1977). 
2. J. -M. Nunzi, C. R. Physique 3, 523 (2002).

3. L. J. A. Koster, V. D. Mihailetchi, and P.W. M. Blom, Appl. Phys. Lett. 88, 093511 (2006).

4. M. C. Scharber, D. Mühlbacher, M. Koppe, P. Denk, C. Waldauf, A. J. Heeger, and C. J. Brabec, Adv. Mater. 18, 789 (2006).

5. M. Svensson, F. Zhang, S. C. Veenstra, W. J. H. Verhees, J. C. Hummelen, J. M. Kroon, O. Inganäs, and M. R. Andersson, Adv. Mater. 15, 988 (2003).

6. X. Wang, E. Perzon, J. L. Delgado, P. de la Cruz, F. Zhang, F. Langa, M. R. Andersson, and O. Inganäs, Appl. Phys. Lett. 85, 5081 (2004).

7. A. Gadisa, X.Wang, S. Admassie, E. Perzon, F. Oswald, F. Langa, M. R. Andersson, and O. Inganäs, Org. Electronics 7, 195 (2006).

8. F. Zhang, K. G. Jespersen, C. Björström, M. Svensson, M. R. Andersson, V. Sundström, K. Magnusson, E. Moons, A. Yartsev, and O. Inganäs, Adv. Funct. Mater. 16, 667 (2006).

9. K. G. Jespersen, F. Zhang, A. Gadisa, V. Sundström, A. Yartsev, and O. Inganäs, Org. Electronics 7, 235 (2006).

10. N. Persson, M. Schubert, and O. Inganäs, Sol. Energy Mater. Sol. Cells 83, 169 (2004).

11. R. Pacios, D. D. C. Bradley, J. Nelson, and C. J. Brabec, Synth. Met. 137, 1469 (2003).

12. Q. Zhou, Q. Hou, L. Zheng, X. Deng, G. Yu, and Y. Cao, Appl. Phys. Lett. 84, 1653 (2004).

13. D. Veldman, T. Offermans, J. Sweelssen, M. M. Koetse, S. C. J. Meskers, and R. A. J. Janssen, Thin Solid Films 511, 333 (2006).

14. D. Veldman, J. J. A. M. Bastiaansen, B. M. W. Langeveld-Voss, J. Sweelssen, M. M. Koetse, S. C. J. Meskers, and R. A. J. Janssen, Thin Solid Films 511, 581 (2006).

15. A. C. Morteani, P. Sreearunothai, L. H. Hertz, R. H. Friend, C. Silva, Phys. Rev. Lett., 92, 247402-1 (2004).

16. H.A.M. van Mullekom, J.A.J.M. Vekemans, E.W. Meijer, Chem. Eur. J. 4, 7 (1998).

17. J. K. J. van Duren, X. Yang, J. Loos, C. W. T. Bulle-Lieuwma, A. B. Sieval, J. C. Hummelen, and R. A. J. Janssen, Adv. Funct. Mater. 14, 425 (2004).

18. Reyes-Reyes, K. Kim, and D. L. Carroll, Appl. Phys. Lett. 87, 083506 (2005).

19. P.W. M. Blom, M. J. M. de Jong, and J. J. M. Vleggaar, Appl. Phys. Lett. 68, 3308 (1996).

20. M. A. Lampert and P. Mark, Current injection in solids (Academic, New York, 1970).

21. P. W. M. Blom, M. J. M. de Jong, and M. G. van Munster, Phys. Rev. B. 55, R656 (1997).

22. D. M. Pai, J. Chem. Phys. 52, 2285 (1970).

23. H. Bässler, Phys. Status Solidi B 175, 15 (1993).

24. W. D. Gill, J. Appl. Phys. 43, 5033 (1972).

25. P. N. Murgatroyd, J. Phys. D: Appl. Phys. 3, 151 (1970).

26. C. Melzer, E. J. Koop, V. D. Mihailetchi, and P. W. M. Blom, Adv. Funct. Mater. 14, 865 (2004).

27. B. A. Gregg, S. Chen, and R. A. Cormier, Chem. Mater. 16, 4586 (2004).

28. B. A. Gregg, J. Phys. Chem. 108, 17285 (2004).

29. B. A. Gregg, S. E. Gledhill, and B. Scott, J. Appl. Phys. 99, 116104 (2006).

30. A. J. Mozer and N. S. Sariciftci, Chem. Phys. Lett. 389, 438 (2004). 